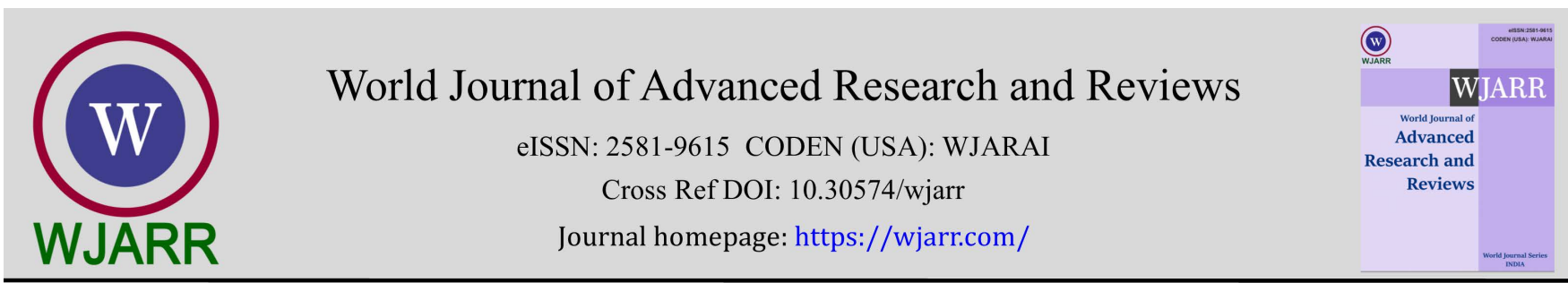

(REVIEW ARTICLE)

\title{
Strategies for coping with frontier technologies and innovations in Africa
}

\author{
Felix Chukwuma Aguboshim ${ }^{1,}{ }^{*}$, Ifeyinwa Nkemdilim Obiokafor ${ }^{2}$ and Irene Nkechi Onwuka ${ }^{3}$ \\ ${ }^{1}$ Department of Computer Science, Federal Polytechnic, Oko, Nigeria. \\ 2 Department of Computer Science Technology, Anambra State Polytechnic, Mgbakwu, Nigeria. \\ ${ }^{3}$ Department of Economics, Nnamdi Azikiwe University, Awka, Nigeria.
}

World Journal of Advanced Research and Reviews, 2021, 11(01), 022-028

Publication history: Received on 01 June 2021; revised on 04 July 2021; accepted on 08 July 2021

Article DOI: https://doi.org/10.30574/wjarr.2021.11.1.0307

\begin{abstract}
Recent advancements in Frontier Technologies and Innovations (FTI), including artificial intelligence, robotics, and biotechnology have shown significant and tremendous potentials for sustainable development globally. Despite this, Africa appears to be unprepared to equitably use or adopt these technological innovations. Evidence has shown that the ongoing global growth in FTI negatively impacts Africa with multifaceted inequalities ranging from poor global class, persistent poverty, disparities in income-earning opportunities, internet usage, pay gap, poor standards of education and health, etc., resulting majorly from poor adoption of technological innovations and favorable Information and Communication Technology (ICT) policies, culture, ethics, and values. Significant digital divides were evident between the technologically advanced countries and backward countries such as Africa during the COVID-19 pandemic because technological innovations have become critical tools for addressing the spread of the disease. This study highlights the strategy for coping with FTI for sustainable development in Africa. The Unified Theory of Acceptance and Use of Technology (UTAUT) was adopted as the study conceptual framework. UTAUT model claims that users' acceptance behavior toward technology is determined by users' decision to use technology and the perceived benefits thereof. The researchers explored a narrative review, analysis, and synthesis of vast works of literature that revealed significant information on strategies for coping with FTI in Africa. The researchers also conjointly extracted peer-reviewed articles among the last five years from electronic databases, engaging some keywords like "Frontier Technologies and Innovations in Africa' 'Coping with Frontier Technologies and Innovations' leveraging resources of Africa via Technology and Innovation", etc. Results show that global progress was associated with sharper inequality between countries, with widening disparities in FTI adoption, literacy level, and access to products, social services such as ICT infrastructure, electrification, education, and health. Results also show that literacy empowerment in Africa especially among women, on technology adoption, policies, culture, ethics, and values may advance sustainable goals, leverage their literacy abilities for FTI adoption, and close widening gaps and inequalities in global FTI.
\end{abstract}

Keywords: Frontier Technologies; Frontier Innovations; ICT innovations; Information Technology (IT) Adoption; IT policies; Ethics

\section{Introduction}

Frontier Technologies and Innovations (FTI) can be referred to as technology that is being applied in new contexts. For instance, robots are not new, but using them to collect offerings in churches during the COVID-19 pandemic for the first time would make their use as frontier technology. The same can be said for drones that are now used to deliver vaccines to remote regions of a country or continent for the first time. Drones can be instructed to help perform medical care, they are ordered to deliver blood and vaccines near (remote) hospitals, get emergency care packages, medicine, food, and water delivered to a specific disaster location [14] and [35]. In some frontier technology innovations, drones are

\footnotetext{
${ }^{*}$ Corresponding author: Felix Chukwuma Aguboshim

Department of Computer Science, Federal Polytechnic, Oko, Nigeria.

Copyright (C) 2021 Author(s) retain the copyright of this article. This article is published under the terms of the Creative Commons Attribution Liscense 4.0.
} 
equipped with loudspeakers to send messages across to citizens on the need to respect COVID-19 measures: social distancing, wearing of masks, follow good respiratory hygiene, and confinement measures among others [8].

FTI otherwise referred to as 'emerging technology' is the next phase in the evolution of modern technology that involves the intelligent combination of radical forward-thinking, simulation, and real-world implementation. In a more concise definition, FTI is seen as technological advancements or innovations, though have passed through the research and development phase, but have not yet been mass-produced or marketed, or adopted by the mainstream. Examples of frontier technologies and innovations include robotics and Artificial Intelligence (AI), autonomous vehicles, machine learning, blockchain technology, drones, renewable energy, fabric-based wearable sensors, and augmented reality [35]. Machine learning is a new frontier technology solution that emerged from AI, now being used to explore the simulation and construction of algorithms that can learn from and make predictions on data sets. Autonomous vehicles are now designed to replace traditional motorized vehicles to make traveling a lot safer. Blockchain or distributed ledger technology has seen steady growth since the last decade, introducing the world to the peer-to-peer electronic cash system called Bitcoin. Fabric-based wearable sensors are now, applicable in areas of health monitoring, smart prosthetics, and assistive technologies that can enable disabled people to operate motorized equipment using their active organs within their surroundings. FTI, are practical realities of the framework in the evolution of modern technology, to build the future of technological innovations.

These technologies have the abilities and capabilities to create new technology-based solutions that may be implemented later on a large scale and achieve worldwide mainstream adoption. FTI is defined as potentially disruptive technologies that can address large-scale challenges or opportunities, and provide large-scale solutions to real-world problems. It is the intersection where radical forward-thinking and real-world implementations meet, especially in the fields of AI, robotics, 3D printing, blockchain, Internet of Things (IoT), 5G, drones, nanotechnology, gene editing, big data, and solar PV. [32] and [35]. FTI has unlocked new routes to global economic sustainability through agriculture, manufacturing, trade in services, the linking of informal and formal sectors, and domestic interconnectivity by providing enormous potential for effective and efficient government policies and administration in the delivery of public services. Frontier Technologies and Innovations (FTI) can help anticipate and respond to the effects of climate hazards and air pollution through the adoption of state-of-the-art technologies to address environmental impacts. If Africa will join the world to achieve the ambitions of the 2030 Agenda for Sustainable Development, these frontier technologies must work for Africa by redefining her society, improving her environmental sustainability, literacy level, and economy, and transforming social interactions [30], otherwise, Africa will face drastic equity-related and ethical challenges that will put Africa at spillover effects from the rest of the world, especially in the areas of addressing hunger, poverty, mortality, decent jobs, inequality, and environmental sustainability, among others [31]. The economic process of Africa, like other nations, includes reduced unemployment, reduced poverty, reduced inequality, and increased economic growth [20] and [28]. Where these indices: unemployment, poverty, income inequality, illiteracy rate, ICT adoption, and usage are not put in a positive check for increased economic growth and rising income, which are needed for sustainable technological growth, sustainable FTI will remain threatened, and may not be efficiently and effectively inclusive in Africa. Against this background, the authors aim at identifying strategies for coping with frontier technologies and innovations in Africa.

No doubt, FTI has significant importance in Africa especially in the provision of new routes to global economic sustainability, domestic interconnectivity through the enormous potential for effective and efficient government policies and administration in the delivery of public services for sustainable development. Constraints to innovations in Africa are often due to poor literacy rate, digital skills, experience and voluntariness of ICT usage, internet access ([22], p.6), human policy, knowledge capabilities backed by good infrastructure ethics and values [12]. ICT infrastructure is the backbone of many frontier technologies [35]. ICT adoption is encompassing, involving its access, easy to use, and ease of use [17] and [18], storage, processing, and transmission [4]. In a Nation where there is poor ICT adoption (digital divide), there is an accompanying risk of FTI triggering a new frontier technology divide, compounding an already existing digital divide. It is estimated that by 2030, three billion people could still lack internet [35], and many more will have little or no opportunity to reap the benefits of FTI. There is a danger that frontier technologies will not reach the world's poorest people like Africa if serious interventions are not made. As a result, in the coming decades, millions of workers in Africa must be ICT compliant or lose their jobs as over 50\% of total employment could be automated in line with FTI adoption. ICT innovations, adoption, and usability are enablers of Frontier Technologies and Innovations (FTI). Therefore, FTI in Africa can only be meaningful when driven by ICT system interfaces that are perceived as useful and easy-to-use and aligned with Africa's cultural values, literacy level, effort expectancy, social influence, facilitating conditions, ICT policies, rules, goals, and values in a sustainable manner [1] and [2].

Coping with FTI in this context can be described as the effort made by users to master the technology, it's physical and psychological know-how so that it would be easy to use, ease of use, and free of effort. Coping with FTI for research and 
Development (R\&D) in African nations is seen as the manifestation of users' effectiveness, efficiency, and satisfaction in the adoption and usage of the technology to achieve specified goals in a determined context. When the level to which an individual's judgment of his or her capability to organize and execute the courses of action required to use a designated frontier technology is prolonged, perceived self-efficacy, perceived usefulness, and overall usability may fail. This in turn may lead to potential physical and psychological damage to the users' perceived ease of use, and users' confidence in adopting the technology. Users' perceived ease of use of any technological innovation is the primary precursor that determines users' behavioral aim to use a system [33]. Therefore, in Africa, and the context of this study, coping efforts and strategies with FTI are a conscious effort by users, directed towards achieving perceived self-efficacy ([13], p. 214), perceived usefulness, and perceived ease of use ([11], p. 320), social influence [33], and usability [10].

\section{Conceptual Framework}

This narrative study adopted the Unified Theory of Acceptance and Use of Technology (UTAUT) as the conceptual framework. UTAUT is a model proposed by Venkatesh, et al., that claims that users' behaviour towards accepting technologies (frontier technologies) is determined by the degree to which a person believes that using the technology would enhance his or her job performance and the factors that drive users' decision to use it [34]. The theory considers two major factors: (a) users' usage behavior towards the technology, and (b) users' adoption behavior toward intention to use the Technology. UTAUT model proposed four constructs that affect both user adoption behaviour and usage behaviour towards technologies. They include performance expectancy (PE), effort expectancy (EE), social influence (SI), and facilitating conditions (FC), and four moderators: literacy level, gender, age, experience, and voluntariness of use. UTAUT model in recent times has been widely adopted [24] and theoretically justified based on measuring instruments that are quite strong, consistent, valid, and reliable [6] and [37]. UTAUT was adopted as our theoretical foundation to study how these factors: literacy level, ICT adoption, digital skills, experience and voluntariness of use, internet access, human policy, and regulation influence adoption and usage of FTI in Africa.

\section{Literature Review}

Many of the countries whose well-being has improved most in the past five years are in Africa but several African economies remain fragile and suffering from underdeveloped infrastructure, and limited diversification of their productive structure. Literacy rate, internet use, poverty rates, and inequality in many African countries remain unacceptably high. Due to good performance during the last two decades, some Africans have moved closer to the frontier while there are still many African countries in the group that falls behind. Africa, as a developing nation is hindered by demographic changes, existing technological gaps, and high illiteracy rate when compared with developed countries, low economic diversification, weak financing mechanism, and stringent intellectual property rights [32].

While some countries succeed in coping with technological innovations, Africa falls behind. This study attempt to identify some strategies and factors for coping with Frontier Technology and Innovations in Africa. Africa lags behind emerging economies in productivity. Major drivers for coping with FTI include, among others, capital accumulation, institutional conditions, knowledge/human development, and social capital/infrastructural bottlenecks [5]. Knowledge capabilities backed by good infrastructure, human development, openness, and a favourable business environment are essential for coping with FTI [23]. A positive statistically significant relationship exists between Self-Service Technologies (SSTs)' characteristic of functionality, security/privacy, assurance, design, customization, and users' satisfaction/utility gained from using SSTs [26]. Also, Satisfaction/utility gained from using SSTs positively affects service excellence, and mediates the relationship between (a) functionality, (b) enjoyment, (c) security/privacy, (d) assurance, (e) design, (f) convenience, and (g) customization and the service excellence [26]. This is a great and welcome development that speaks toward the impact of SSTs and FTIs on global development. However, this is far from Africa.

One of the most significant barriers to coping with frontiers technology innovations in Africa is poor infrastructure and lack of human development, especially in areas of technology. In Africa and other developing nations, frontier technology innovation is seen from the perspective of their ability to adopt, sustain, and possibly modify new technology products and services, which are new to them, irrespective of whether or not they have long existed elsewhere [5]. African ability to cope with such innovations is dependent on knowledge capabilities backed by good infrastructure, human development, literacy level, openness, favourable ICT policy adoption, and business environment [23]. Africa's poor ICT infrastructure and implementation coupled with lack of human development, especially international cooperation and collaboration, are the most significant barriers to frontier technology catch-up in Africa [35]. Frontier Technology diffusion is rarely automatic [35] and [36]. This is because frontier technologies are more than real [21], and are often only accessible to a small group of literate people or sectors before mainstream adoption. In extreme cases, some technologies may not go beyond the laboratory. Other reasons while some technologies, despite their 
technical superiority, may not be commercially viable or affordable for some groups of people or communities because the nation's economic development, market introduction, growth, maturity, and sometimes poor usability due to ethical concerns ranging from the impact of automation on jobs by robots, concerns relating to data security and privacy as in the case of IoT, data is collected by service providers and how the data are used. Numerous investigations have shown gender gaps in internet use (23\%), literacy rate (48.6\%), pay gap (22\%), as posing significant barriers to frontier technology catch-up in Africa [3] and [27].

Strategies for frontier technology catch-up in Africa may include: inclusive ICT infrastructure; developing a workforce fit for a fourth industrial revolution future; developing innovative regulatory frameworks; incentivizing responsible frontier technology development in the private sector; catalyzing the role of government in frontier technologies' evolution; and creating a platform for multi-stakeholder, regional, and international cooperation [36]. Stakeholders and policymakers should encourage ICT literacy through the acquisition of the necessary digital skills and competencies to adapt frontier technologies into their countries, especially among countries that are weak and prone to systemic failures and structural deficiencies. Frontier technologies demand greater digitalization and connectivity. Therefore, adequate incentives and subsidies should be provided not just for internet access but also for the devices through which people get connected. Africa's innovation systems must be strengthened before she can effectively adopt frontier technologies and be able to master many existing technologies.

\section{Methodology}

The researchers reviewed, analyzed, and synthesized significant research pieces of evidence and findings based on the study conceptual framework and existing challenges that plagued FTI adoption and sustainability in Africa. A narrative review methodology is adopted where the study can be described as descriptive or explanatory [9] and [25], and where analysis and synthesis of different and related research findings are required to draw holistic interpretations or conclusions based on the reviewers' own experience, existing theories, and models [16] and [27]. Narrative studies have great abilities and capabilities to capture and comprehend the diverse and numerous insights around scholarly research topics and the opportunity to extract from vast literature, reflective practices, shared views, and knowledge [19]. Within the context of this narrative study, the researchers reviewed a vast of peer-reviewed articles in line with the identified keywords, term identification, article identification, quality assessment, data extraction, and data synthesis.

\section{Data Collection}

Data collection came from reviewed research findings that are relevant and related to our study. The researchers collected data from the ProQuest databases, ScienceDirect, Google scholar, Walden University international library databases, and other related peer-reviewed texts. We used phrases and terms as key search words in the databases for related literature on strategies for coping with frontier technologies and innovations in Africa. Phrases and terms engaged included "frontier technologies and innovations in Africa", "How to cope with frontier technologies in Africa", "leveraging frontier technologies and innovations divide among Africa", and many others. Our reviews incorporated 35 references. Twenty-two (91\%) of total references incorporated in the study is peer-reviewed, while twenty-two (68\%) are peer-reviewed journals that are within the last 5 years.

\section{Discussion and Findings}

Frontier technologies demand complex digitalization and connectivity. The contribution of any frontier technology can only produce meaningful and effective economic impact where ICT innovations are properly implemented, widely valued, diffused, and used [1]. Sustainable ICT has been identified as a vital enabler of FTI in any nation. Surprisingly, there are shreds of evidence that suggest that there are no remarkable sustainable ICT services for sustainable FTI and economic productivity in Africa majorly due to significant gender gaps in internet use (23\%), literacy rate (48.6\%), pay gap (22\%), political ambition, educational outcomes, etc., as a result of restrictions placed by culture, ethics, and values that failed to recognize gender equality in these areas, especially for African women [3], [7] and [29]. Other reasons for no remarkable sustainable ICT services for sustainable FTI and economic productivity in Africa include corrupt policies, poor usability of ICT systems, non-adherence to ICT international policies and standards, and not placing required value on ICT by users [15]. There is significant evidence that FTI adoption in Africa has remained weak and vulnerable due to corrupt practices and non-adherence to ICT policies and ethics that increasingly exploit ICT sustainability and adversely affect FTI adoption.

Findings showed that significant barriers to frontier technology catch-up in Africa included, among others: poor ICT infrastructure and implementation, lack of human development, and international cooperation and collaboration [35] 
and [36]. Awareness, training, and sensitization for people to understand and perceive available technological innovations as useful and easy-to-use are very vital and must be put in place as part of the strategies to cope with FTI adoption in Africa. Existing ICT infrastructures, their usability, procurement, and implementation in preparation for sustainability FTI in Africa must be reviewed and designed to meet the required standards for FTI adoption.

\section{Conclusion}

In all facets of life and all countries, human development has been driven by sustainable frontier technological innovations. Also driven by sustainable frontier technological innovations are sharp and staggering inequalities among and within countries. This is because the pace of technological change varies with the countries' literacy ability, digitization, and ICT adoption. As a result, frontier technological innovations or new technologies can bring about severe downsides if these technologies outpace the countries or society's abilities and capabilities to adapt. Sometimes these transmissions of inequalities become intergenerational as the technological gap created in one generation affects or slowdown the opportunities for the next generation. United Nations' technological and innovation report testify to this intergenerational transmission of inequalities due to the advancement of frontier technological innovations [32]. According to the report, the contribution of between-country inequality to global inequality rose from $28 \%$ to $85 \%$ between the years eighteen hundred and twenty and two thousand and two.

Africa may not effectively benefit from the global 2030 Agenda for Sustainable Development Goals designed to address poverty, mortality, and economic inequality or technological divide without utilizing and integrating frontier technologies. FTI is a healthy platform in addressing all forms of digital challenges that impact negatively Africa. The study suggests digital solutions as part of strategies to cope with FTI in Africa to include, among others, ICT literacy through the acquisition of the necessary digital skills and competencies to adapt frontier technologies into their countries. Frontier technologies demand greater digitalization and connectivity. Therefore, adequate incentives and subsidies should be provided not just for internet access but also for the devices through which people get connected. Most developing countries are weak and prone to systemic failures and structural deficiencies [27]. Africa's innovation systems must be strengthened before she can effectively adopt frontier technologies and be able to master many existing technologies. Findings from this study were significant and supported by organizational documents and current literature on strategies for coping with FTIs, their adoption, and sustainability. Findings are also consistent with the UTAUT conceptual framework of this study. Therefore, findings from this study may have greater applicability to other developing nations that are FTI dependent.

\section{Compliance with ethical standards}

\section{Acknowledgments}

Our sincere appreciation and thanks to Dr. Felix. Chukwuma. Aguboshim for his wonderful contributions.

\section{Disclosure of conflict of interest}

There are no conflicts of interest.

\section{References}

[1] Aguboshim FC. Strategies for Enhancing ICT Innovations System Security in Nigeria. International Journal of Advances in Engineering and Management (IJAEM). 2021; 3(2): 37-43.

[2] Aguboshim FC, Chijioke IA. Women in ICT: An Essential Strategy for Sustainable Women Empowerment, Productivity, and Economic Development in Nigeria International Journal of Scientific \& Engineering Research. 2019; 10(9): 1598-1603.

[3] Aguboshim FC, Obiokafor IF, Onwuka IN. Women in Africa: Leveraging ICT in Closing the Gender Gap through Ethics and Values. International Journal of Trend in Scientific Research and Development (IJTSRD). 2020; 4(6): 1655-1660.

[4] Allassani W. Determining factors of bank employee reading habits of information security policies. Journal of Information Systems and Technology Management. 2014; 11(3): 533-548.

[5] Andrews D, Criscuolo C, Gal PN. The Future of Productivity: Main Background Papers Frontier Firms, Technology Diffusion and Public Policy: Micro Evidence from OECD Countries. 2015. 
[6] Arumugam A, Yahya D, Rozalina K, Mohd R. Usage of Learning Management System (Moodle) among Postgraduate Students: UTAUT Model. Asian Social Science. 2014; 10(14): 186-192.

[7] Asante-Apeatu TS. West African Boardrooms and the gender gap. Good Governance Africa. Uncategorized. 2018.

[8] AUDA-NEPAD. White Paper: Harnessing Innovation and Emerging Technologies to Address the Impact of COVID19 in Africa African Union High-Level Panel on Emerging Technologies. African Union Development Agency NEPAD (AUDA-NEPAD). 2020.

[9] Bell EE. A Narrative Inquiry: A Black Male Looking to Teach. The Qualitative Report. 2017; 22(4): 1137-1150.

[10] Conti V, Collotta M, Pau G, Vitabile S. Usability Analysis of a Novel Biometric Authentication Approach for Android-Based Mobile Devices. Journal of Telecommunications and Information Technology. 2014; 4: 34-43.

[11] Davis FD. Perceived usefulness, perceived ease of use, and user acceptance. MIS Quarterly. 1989; 13(3): $319-340$.

[12] Egbetokun A, Atta-Ankomah R, Jegede O, Lorenz E. Firm-level innovation in Africa: overcoming limits and constraints, Innovation and Development. 2016; 6(2): 161-174.

[13] Fathema F, Shannon D, Ross M. Expanding the Technology Acceptance Model (TAM) to Examine Faculty Use of Learning Management Systems (LMSs) In Higher Education Institutions. MERLOT Journal of Online Learning and Teaching. 2015; 11(2): 210-232.

[14] Giallourakis A. Africa: The World's Next Economic Frontier? How innovative and new business models are shaping Africa and influencing the global and regional economies. 2020.

[15] GreavuSerban V, Serban 0. Social Engineering a General Approach. Informatica Economica. 2014; 18(2): 5-14.

[16] Hill C, Burrows G. New voices: The usefulness of a narrative approach to social work research. Qualitative Social Work: Research and Practice. 2017; 16(2): 273-288.

[17] Hoehle H, Zhang X, Venkatesh V. An espoused cultural perspective to understand continued intention to use mobile applications: a four-country study of mobile social media application usability. European Journal of Information Systems, suppl. Special Issue: Cross-Cultural IS Research: Perspectives. 2015; 24(3), 337-359. ITU. (2020). Frontier technologies to protect the environment and tackle climate change. International Telecommunication Union. 2020.

[18] Jin C. Adoption of e-book among college students: The perspective of an integrated TAM. Computers in Human Behavior. 2014; 41(1): 471-477.

[19] Malcolm PM. Peer support in mental health: a narrative review of its relevance to social work. Egyptian Journal of Social Work. 2017; 4(1): 19-40

[20] Mazanai M, Nieuwenhuizen C. Motivations and unique challenges of successful foreign-owned small and medium enterprises in South Africa. Development Southern Africa. 2021; 1-18.

[21] McLean J. Frontier Technologies and Digital Solutions: Digital Ecosystems, Open Data, and Wishful Thinking. Anthropocenes - Human, Inhuman, Posthuman. 2020; 1(1): 4.

[22] National Information Technology Development Agency (NITDA). Framework and guidelines for public internet access (PIA). 2019; 1-14.

[23] OECD. Innovation for Development. A Discussion Of The Issues And An Overview Of Work Of The OECD Directorate For Science, Technology And Industry May 2012 Organisation For Economic Co-Operation And Development (OECD). 2012.

[24] Oye ND, Alahad N, Abrahim N. The history of UTAUT model and its impact on ICT acceptance and usage by academicians. Education and Information Technologies. 2014; 19(1): 251-270.

[25] Privizzini A. The Child Attachment Interview: A Narrative Review. Frontiers in Psychology. 2017; 8(1).VH

[26] Safaeimanesh F, Kılıç H, Alipour H, Safaeimanesh S. Self-Service Technologies (SSTs)-the Next Frontier in Service Excellence: Implications for Tourism Industry. Sustainability. 2021; 13(5): 2604.

[27] Scarnato JM. The value of digital video data for qualitative social work research: A narrative review. Qualitative Social Work: Research and Practice. 2017.

[28] Schumacher R. Adam smith and the 'rich country-poor country' debate: Eighteenthcentury views on economic progress and international trade. The European Journal of the History of Economic Thought. 2016; 23(5): 764-93. 
[29] United Nations. United Nations on Conference and Development. Achieving the Sustainable Development Goals through Consumer Protection. United Nations Conference on Trade and Development. 2017.

[30] United Nations. Managing the promises of frontier technologies. World Economic and Social Survey. 2018a; 3964.

[31] United Nations. Frontier technologies for a sustainable future. World Economic and Social Survey. 2018b; 9-38.

[32] United Nations. United Nations on Conference and Development. Technology and Innovation Report. Prosperity for all. 2021.

[33] Venkatesh V, Davis FD. A theoretical extension of the technology acceptance model: four longitudinal field studies. Management Science. 2000; 46(2): 186-204.

[34] Venkatesh V, Morris MG, Davis GB, Davis FD. User Acceptance of Information Technology: Toward a Unified View. MIS Quarterly. 2003; 27(3): 425.

[35] Wrong J, Wrong T. Frontier Technologies for Sustainable Development in Asia and the Pacific. The United Nations Economic and Social Commission for Asia and the Pacific (UNESCAP). 2018.

[36] Zhenmin L. Frontier Technologies: A Window of Opportunity for Leapfrogging! The World Economic and Social Survey 2018: Frontier Technologies for Sustainable Development. 2018.

[37] Zhou T, Lu Y, Wang B. Integrating TTF and UTAUT to explain mobile banking user adoption. Computers in Human Behavior. 2010; 26(4): 760-767.

\section{Author's short Biography}

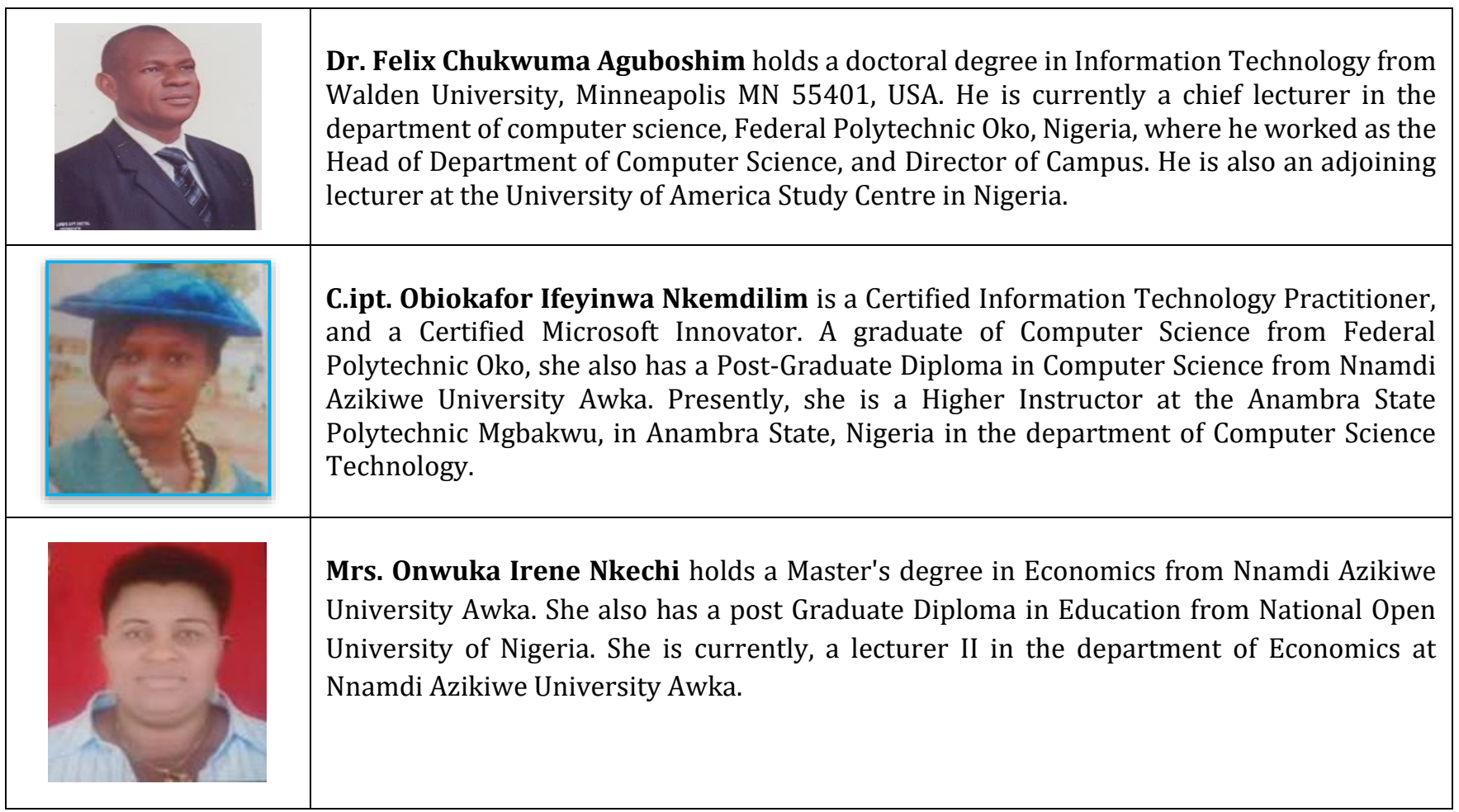

